\title{
Application of La-ZSM-5 Coated Silicon Carbide Foam Catalyst for Toluene Methylation with Methanol
}

\author{
Debarpita Ghosal, Jayanta Kumar Basu, Sonali Sengupta* \\ Department of Chemical Engineering, Indian Institute of Technology Kharagpur, India -721302
}

Received: 9th December 2014; Revised: 27th April 2015; Accepted: 29th April 2015

\begin{abstract}
The performance of toluene methylation reaction was studied by H-ZSM-5 modified with La, Ce and $\mathrm{Nb}$ at different percentage loading and found that $10 \%$ metal loading is producing the best performance in the reaction in terms of toluene conversion. The catalyst was coated on silicon carbide foam support which showed better conversion than the pelleted catalyst. Again, among the treated and untreated H-ZSM-5, the La-ZSM-5 catalyst is chosen for the reaction for its highest selectivity towards xylene, the main product. All catalysts were characterized in terms of surface properties, SEM, XRD and $\mathrm{NH}_{3}$-TPD. Kinetic study was done by La-ZSM-5 with $10 \%$ loading. Langmuir Hinshelwood kinetic model with surface reaction as rate controlling step was selected as the rate equation. The activation energy was found to be $47 \mathrm{~kJ} / \mathrm{mol}$. (c) 2015 BCREC UNDIP. All rights reserved.
\end{abstract}

Keywords: La-ZSM-5; silicon carbide foam; methylation reaction; kinetic study

How to Cite: Ghosal, D., Basu, J.K., Sengupta, S. (2015). Application of La-ZSM-5 Coated Silicon Carbide Foam Catalyst for Toluene Methylation with Methanol. Bulletin of Chemical Reaction Engineering \& Catalysis, 10 (2): 201-209. (doi:10.9767/bcrec.10.2.7872.201-209)

Permalink/DOI: http://dx.doi.org/10.9767/bcrec.10.2.7872.201-209

\section{Introduction}

Transition metal and rare earth metal modified zeolites have been extensively explored in different fields of chemical and petrochemical reactions. Any zeolite is considered to be a good acidic catalyst to promote alkylation reactions. The rare earth and transition metals have the intrinsic characteristics of partially filled $f$ and $\mathrm{d}$ orbital in their electronic configuration. Thus, when those materials are impregnated into the zeolite they can enhance the catalytic activity of zeolite by increasing its acidic nature.

Many literatures have been found about the alkylation reaction catalysed by metal modified

\footnotetext{
${ }^{*}$ Corresponding author.
}

E mail: sonalis.iitkgp@gmail.com (S. Sengupta) Tel: +91-3222-283954, Fax : +91-3222-282250
ZSM-5 and other zeolite catalyst. Aboul-Gheit et al. $[1,2]$ investigated the enhancement of the para xylene selectivity through alkylation of toluene with methanol catalysed by platinum modified HZSM-5 and the same reaction with the Pd-ZSM-5 to increase para xylene formation. Side-chain alkylation of 4-picoline with formaldehyde using alkali-modified ZSM-5, zeolite-X, Y and mordenite was studied [3]. Alkylation of benzene with benzyl chloride to produce mainly diphenyl methane using $\mathrm{Fe}, \mathrm{Zn}$, Ga, In modified ZSM-5 and different alumino silicate of MFI structure were summarized by Choudhury et al. [4]. The same reaction was studied using Fe-ZSM-5 [5]. Barrows et al. [6] found the effects of $\mathrm{Nb}$ on ZSM-5 where it was observed the change of structural property of HZSM-5 at different percentage of $\mathrm{Nb}$ impregnation. The characterization and catalytic performance of niobic acid dispersed over titanium 
silicate was investigated in 1-octene epoxidation [7]. Moreira et al. [8] explained the nature and position of cerium in Ce-loaded Y zeolite and determined the catalytic performance in 2 propanol dehydration. A report on isoprpylation of naphthalene over cerium impregnated mordenite was found, where the emphasis was made on the shape selective alkylation and deactivation of active acid sites by cerium [9]. Liu et al. [10] explained the catalytic behavior of molybdenum modified zeolites, silica and alumina on the dehydroaromatisation of methane to benzene and naphthalene. The synergistic role of acid sites in the Ce-impregnated mesoporous MCM-41 catalyst in benzylation of toluene was also reported [11].

Hartford et al. [12] prepared product selective catalyst, La-ZSM-5, for propene oligomerisation and hexane cracking, where La loading decreases the strong acid site while increases the weak acid sites. It has also been reported that rhodium on alumina supported over ceramic foam enhanced the catalytic activity compared to the pellet form [13]. La-exchanged USY and beta zeolites were used by Wahlen $e t$ al. [14] in disproportionation reaction of hydrogen peroxide into singlet oxygen. A study on the aromatization of methanol with coimpregnated La, Zn-ZSM-5 has been reported $[15,16]$. Bendahou et al. [17] found out the influence of La-doped mesoporous SBA-15 on the performance of Pt/SBA-15 and Pd/SBA-15 catalysts for total oxidation of toluene. The synergistic role of La as promoter to H-ZSM-5 for dehydration of ethanol was studied [18].

The objective of the present work is the preparation of La, Ce and $\mathrm{Nb}$ modified ZSM-5 catalyst coated over silicon carbide ( $\mathrm{SiC}$ ) ceramic foam and comparative study of their physical properties as well as their performance towards toluene alkylation reaction with methanol. The products obtained are xylenes as major product and trimethyl benzene, benzene and water as by products. The reaction is performed varying different process conditions such as, methanol to toluene mole ratio; toluene feed rate, temperature and ratio of weight of catalyst to molar feed rate with the selected catalyst, La/ZSM-5. The experiments include reusability studies with regeneration of catalyst. Eley-Riedel based kinetic model has been proposed for the toluene alkylation reaction with methanol.

\section{Materials and Methods}

\subsection{Materials and Experimental Methods}

Commercial H-ZSM-5 (Sud Chemie India
Ltd.), cerium nitrate, lanthanum nitrate (Spectrochem Pvt. Ltd, India) and niobium chloride (Stren Chemicals, India) were used for the preparation of metal modified catalysts. Toulene (Merck India Ltd.), methanol (Spectrochem Pvt. Ltd.), all analytical grade, were used for the reaction. Silicon carbide foam $(40 \mathrm{~mm} \times 40 \mathrm{~mm} \times 15 \mathrm{~mm}, 30 \mathrm{ppi}$ and $10 \mathrm{ppi})$ procured from Foseco India Ltd. was used as catalyst support.

Washcoating or dipcoating is a usual technique to load powdered catalyst over structural support like $\mathrm{SiC}$ foam. The foam blocks were washed with distilled water followed by acetone and then dried in an oven for $3 \mathrm{~h}$ prior to dipcoating.

Dipcoating was performed in a Single Dip Coater (model SDC 2007C) supplied by Apex Instruments Ltd., India. The coating was performed by dipping the foams in slurry of catalyst powder for a definite period of time in the dipcoater. Typical slurry of catalyst in water consisting of $20 \mathrm{~g}$ catalyst powder, $5 \mathrm{~g}$ aluminium nitrate as binder and $7 \mathrm{~g}$ starch as viscosity modifier was prepared. After coating process, the excess slurry adhered to the pores of foam was removed by flushing with air. The foam blocks were then dried at $120{ }^{\circ} \mathrm{C}$ for $3 \mathrm{~h}$ and calcined at $550{ }^{\circ} \mathrm{C}$ for another $3 \mathrm{~h}$. The coating step was repeated for several consecutive times to obtain the desired catalyst amount with perfect adherence.

The impregnation of metals on HZSM- 5 was carried out by both wet and dry impregnation method. In typical dry impregnation method, the volume of metal-containing solution was added to previously activated H-ZSM-5 that should exactly fill up the void volume of the pores of the catalyst. In wet impregnation, the solution taken was sufficiently excess to ensure the complete filling up of the pores of the catalyst. Water was used as solvent for La and Ce, whereas, ethyl alcohol was used for $\mathrm{Nb}$. The first step of impregnation by wet process was to mix specific amount of HZSM-5 with definite amount of metal precursor solution with thorough mixing. After keeping the slurry undisturbed overnight at room temperature, it was filtered, dried at $120{ }^{\circ} \mathrm{C}$ for $3 \mathrm{~h}$ and calcined at $540{ }^{\circ} \mathrm{C}$ for $5 \mathrm{~h}$. In dry impregnation method, metal precursor solution was added to HZSM-5 which was absorbed totally by the catalyst powder. The rest part of the process was the same as before except the filtration step. The impregnation method was repeated for metal precursor solutions of different concentrations to get different batches of metal deposited catalyst. 
The experimental set up mainly consists of a feed inlet syringe pump (Miclins-SP-01, Miclins India Ltd.), preheater, reactor and sample collector. The reactor is made up of a stainless steel rectangular shaped $(45 \mathrm{~mm} \times 45 \mathrm{~mm} \times$ $200 \mathrm{~mm}$ ) vessel accommodated in an electrically heated furnace, which was properly insulated and exactly mimicking the reactor. The catalyst coated silicon carbide foam block was placed at the middle of the reactor. A thermocouple was inserted at the middle of the reactor. The maximum allowable temperature of the reactor is $450{ }^{\circ} \mathrm{C}$. The outlet of the reactor is connected with a condenser and the samples are withdrawn at a definite time interval and analysed in gas chromatograph (Chemito, GC 8610) with FID using 2 m OV-17 column

\subsection{Catalyst Characterization}

The surface morphology and microstructural analysis of untreated HZSM-5, its metal modified form, silicon carbide ( $\mathrm{SiC}$ ) foam and catalyst coated foam was performed by Zeiss EVO 60 Scanning Electron Microscope (SEM). SEM was done with a small portion of powdered, moisture-free sample with different scale and magnification as per requirement.

Surface properties of the catalysts were analysed by BET surface area analyser (Autosorb1, Model:ASI MP/Chemi-LP, Quantachrome Instruments, USA). BET analysis is done by nitrogen adsorption-desorption method at relative pressure ranging from $10^{-6}$ to 1 bar. These data were utilized to calculate specific surface area, pore volume, average pore diameter etc.

The surface acidity of the catalyst was determined by temperature programmed desorption technique (TPD) by ammonia using ChemBET-3000-TPD/TPR instrument (Quantachrome Instruments, USA). For analysis, about $0.2 \mathrm{~g}$ of powdered catalyst were taken in a quartz U-shaped tube and degassed in a flow of He at $200{ }^{\circ} \mathrm{C}$. In the next step, He was replaced by $\mathrm{NH}_{3}$ passed at flow rate of $80 \mathrm{ml} / \mathrm{min}$ and saturation with $\mathrm{NH}_{3}$ was done.

The crystalline nature of all powdered catalysts was determined by X-ray diffraction (XRD) with the help of X-ray diffractometer (Model: PW-1710, Philips). The analysed data were compared with standard data base (International centre for diffraction data, 1996). The metal content in each metal modified catalyst was determined by X-ray fluorescence spectroscopy (XRF) using model AX10S, PANalytical.

\section{Results and Discussion}

In this work, $1,2,3,4,5,10,15,20$ and $25 \%$ metal impregnation were targeted over HZSM5. The deposition of the said metals on HZSM-5 by both wet and dry impregnation methods were found to be slightly less than the targeted metal loading value, which had been detected by XRF. For example, when the targeted metal loading were fixed at $10 \%$ and $15 \%$, the actual loading, for La were found to be 7.4 and $11.2 \%$ for wet and 9.8 and $14.4 \%$ for dry impregnation methods respectively. The observed values show that, metal loading is higher in dry impregnation than in wet one. Hence, for experimentation, the dry impregnation method was followed.

\subsection{Optimization of Metal Contents in Catalyst}

Toluene alkylation with methanol was selected as the key reaction for determining the optimum metal content in ZSM-5 catalyst. In this regard, ZSM-5 with metal loading $1-25 \%$ of $\mathrm{La}, \mathrm{Ce}$ and $\mathrm{Nb}$ coated over $\mathrm{SiC}$ foam were employed in the reaction as catalysts and the conversions of toluene to total xylenes (o-, m- and p-xylene altogether) and selectivity of xylenes were compared as a function of targeted metal loading. It is observed that the conversion sharply decreases from lower to higher metal content till the targeted metal content of $10 \%$ and after that the increase in metal loading does not have any effect on conversion. The selectivity of total xylene with $10 \%$ targeted La, $\mathrm{Ce}$ and $\mathrm{Nb}$ loaded ZSM-5 were observed to be 98.8, 94.5 and $92 \%$, respectively. The decrease in conversion after $10 \%$ loading can be explained by the clogging up of the pore mouth of the ZSM- 5 catalysts by excess metal which may inhibit the easy access of the reactants to the active sites in the interior surface. High selectivity may be due to the partial deactivation of active sites which renders the unfavourable side reactions leading to enhanced selectivity. Hence, the targeted metal loading of $10 \%$ on ZSM-5 was selected for further work.

\subsection{Comparison of Surface Properties of Different Metal Loaded Catalysts}

Surface areas of untreated HZSM- 5 and its metal modified form are shown in Table 1. The decrease in surface area of metal loaded ZSM-5 was observed compared to the untreated one. The surface area of metal loaded catalysts decrease in the order of $\mathrm{Nb}>\mathrm{Ce}>\mathrm{La}$ loaded ZSM- 5 although the decrease is very small. Average 
pore size and total pore volume of the catalysts follow the same trend. The decrease in surface area due to metal loading may be explained by the loss in zeolitic structure of ZSM-5 during calcination step of metal loaded catalyst and also by the physical deposition of metal oxides at the pore mouth.

\subsection{SEM Analysis}

SEM images of untreated H-ZSM-5 and 10\% La loaded ZSM-5 catalyst are shown in Figure 1. No appreciable change in particle size and morphology was observed in the images due to metal impregnation rather, an agglomeration of particles was visible in the metal modified catalysts.

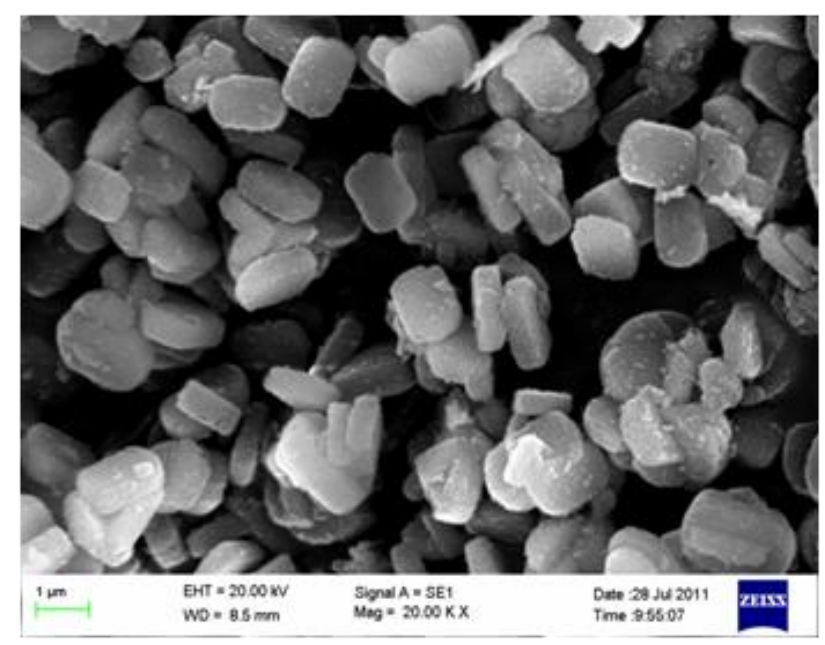

(a)

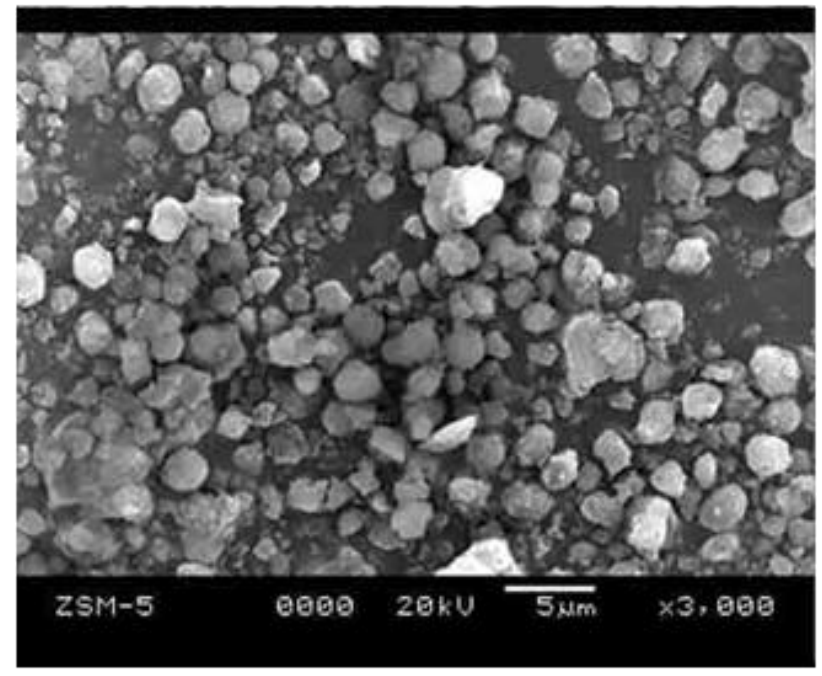

(b)

Figure 1. SEM images of (a) La-ZSM-5, and (b) Untreated HZSM-5

\subsection{XRD Study}

XRD pattern of unmodified and metal modified ZSM-5 catalysts are presented in Figure 2. It is observed that the intensity of XRD peaks of ZSM-5 is slightly decreased in its metal modified forms which may be due to the metal-zeolite interaction in the impregnated samples [2]. The magnitude of the peak intensity for untreated ZSM-5(20=26.850, 27.850 and 28.30 according to ICDD data base) appeared to be decreased in the order, La-ZSM-5>Ce-ZSM-5>Nb-ZSM-5. Henceforth, it can be said that the metal-zeolite interaction is highest for La impregnation and lowest for $\mathrm{Nb}$. Moreover, it can be inferred that due to greater interaction with the zeolite the dispersion of metals is best in La-ZSM-5.

\section{5. $\mathrm{NH}_{3}-\mathrm{TPD}$ Study}

The acid sites of the solid catalysts were measured by $\mathrm{NH}_{3}$ TPD technique. The concentration profile or strength of acid sites may be qualitatively analyzed and compared from the TPD profile (Figure 3) between metal modified and untreated catalysts. The peaks are observed at low as well as high temperature ranges. The area under the curves in the profile represents the amount of acid strengths [19]. The low temperature peaks indicate weak acid sites.

Humps are observed at higher temperature range (400 to $800{ }^{\circ} \mathrm{C}$ ) indicating strong acid sites, which are actually Brönsted acid sites. The impregnation of rare earth and transition metals onto the zeolitic framework of H-ZSM-5 decreased its strong acid sites by blocking several sites of the catalysts and thus deactivating them, which could be observed from the diminishing area of the humps at the temperature range 400 to $800{ }^{\circ} \mathrm{C}$. Therefore, the strong acid sites decrease from H-ZSM-5 to La-ZSM-5 followed by Nb-ZSM-5 and Ce-ZSM-5.

Table 1. Comparison of surface properties of metal modified catalysts

\begin{tabular}{lccc}
\hline \multicolumn{1}{c}{ Sample } & $\begin{array}{c}\text { Surface } \\
\text { area } \\
\left(\mathrm{m}^{2} / \mathrm{g}\right)\end{array}$ & $\begin{array}{c}\text { Total pore } \\
\text { volume } \\
\left(\mathrm{m}^{3} / \mathrm{g}\right)\end{array}$ & $\begin{array}{c}\text { Average pore } \\
\text { diameter }(\mathrm{nm})\end{array}$ \\
\hline Untreated- & 323 & 0.235 & 2.92 \\
ZSM-5 & & & \\
La10ZSM-5 & 291 & 0.196 & 2.54 \\
Ce10ZSM-5 & 296 & 0.206 & 2.73 \\
Nb10ZSM-5 & 302 & 0.214 & 2.82 \\
\hline
\end{tabular}




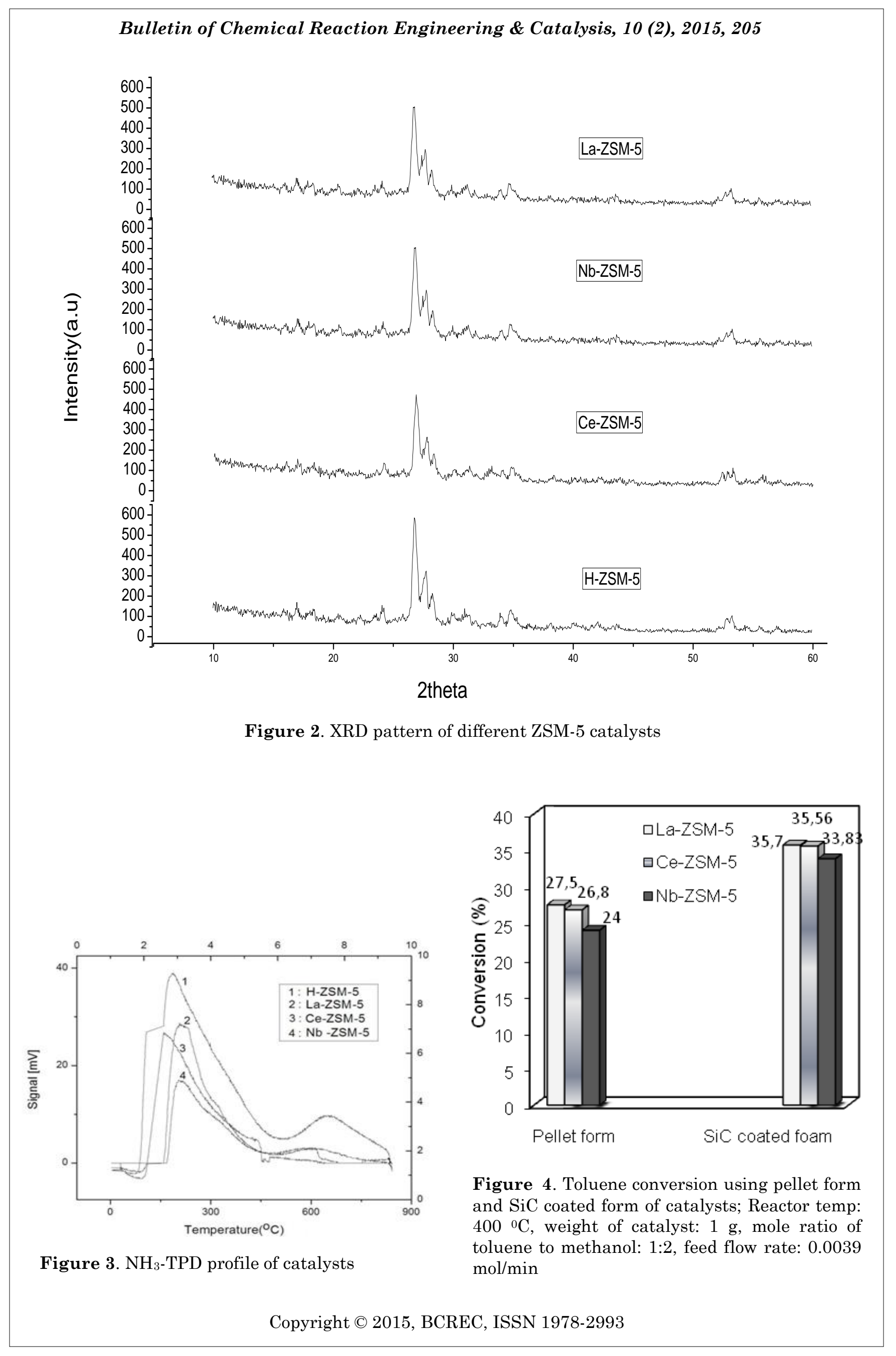




\subsection{Comparison Between Pelleted and SiC Foam Supported Metal Exchanged ZSM-5 Catalysts in Terms of Toluene Conversion}

The performance of the catalysts used in pellet form as well as in the form of coated foams in terms of conversion of toluene, for toluene methylation as the representative reaction is presented in Figure 4. It is observed from figure that, the coated catalysts prove to be the better one compared to the pallet forms.

The increase in conversion using coated catalysts than the pelleted ones are 29.8, 32.7 and $40.95 \%$ for La-ZSM-5, Ce-ZSM-5 and NbZSM-5 catalysts, respectively. This may be due to the thin layer distribution of catalysts over foam surface, which can expose the catalytic surface more than the pelleted ones. La-ZSM-5 was also coated on 10 ppi $\mathrm{SiC}$ foam and the conversion obtained is compared with La-ZSM-

Table 2. Conversion of toluene and selectivity of xylenes on different catalysts

\begin{tabular}{ccc}
\hline Catalyst & $\begin{array}{c}\text { Conversion at } \\
55 \min \left(400^{\circ} \mathrm{C}\right) \\
(\%)\end{array}$ & $\begin{array}{c}\text { Selectivity of } \\
\text { xylenes }(\%)\end{array}$ \\
\hline H-ZSM-5 & 37 & 85 \\
La-ZSM-5 & 35.7 & 98 \\
Ce-ZSM-5 & 29.8 & 95 \\
Nb-ZSM-5 & 25.2 & 92 \\
\hline
\end{tabular}

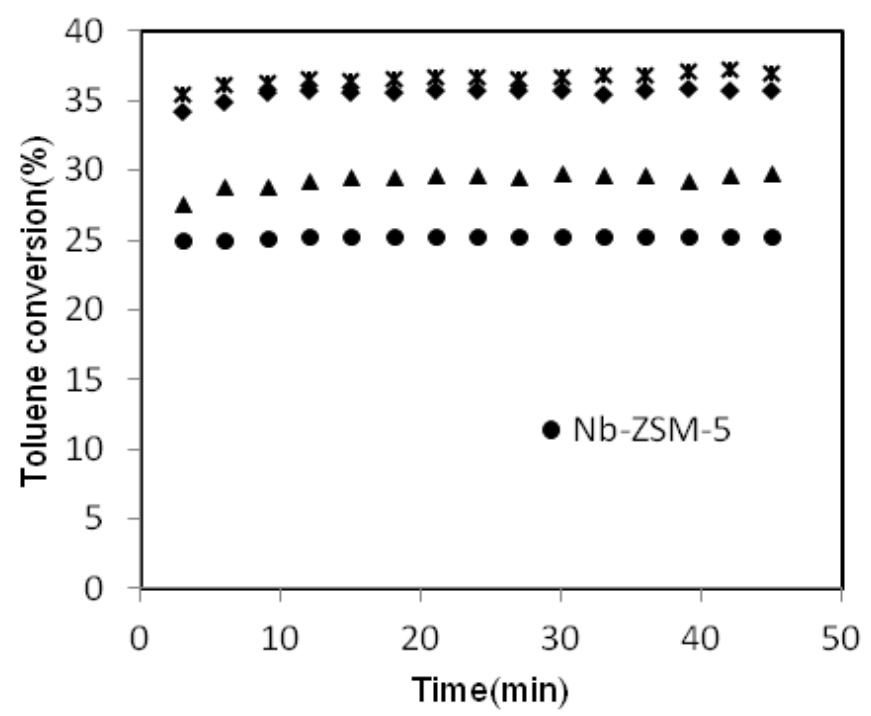

Figure 5. Time-on-stream toluene conversion profile. Reactor temp.: $400{ }^{\circ} \mathrm{C}$, weight of catalyst: $1 \mathrm{~g}$, mole ratio of toluene to methanol: $1: 2$, feed flow rate: $0.0039 \mathrm{~mol} / \mathrm{min}$

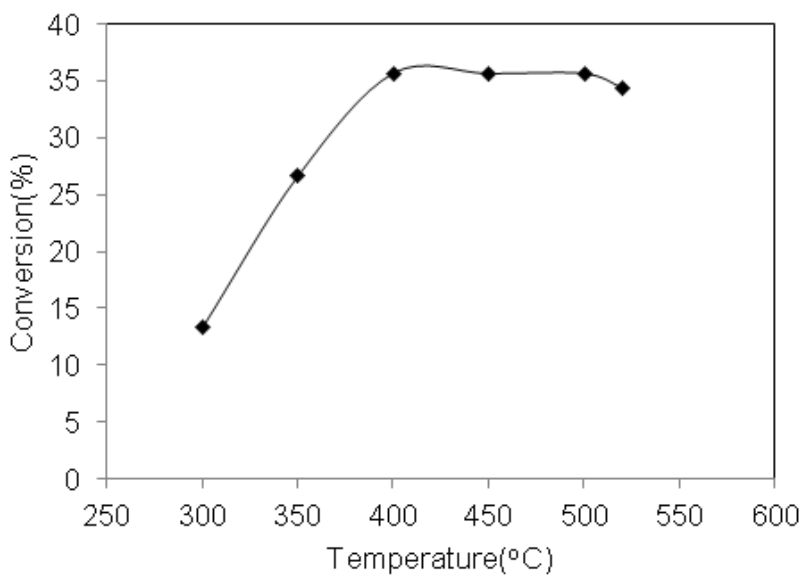

Figure 6. Effect of temperature on toluene conversion. Weight of catalyst: $1 \mathrm{~g}$, mole ratio of toluene to methanol: 1:2, feed flow rate: 0.0039 $\mathrm{mol} / \mathrm{min}, \mathrm{N}_{2}$ flow rate: $2 \times 10^{-4} \mathrm{~mol} / \mathrm{min}$

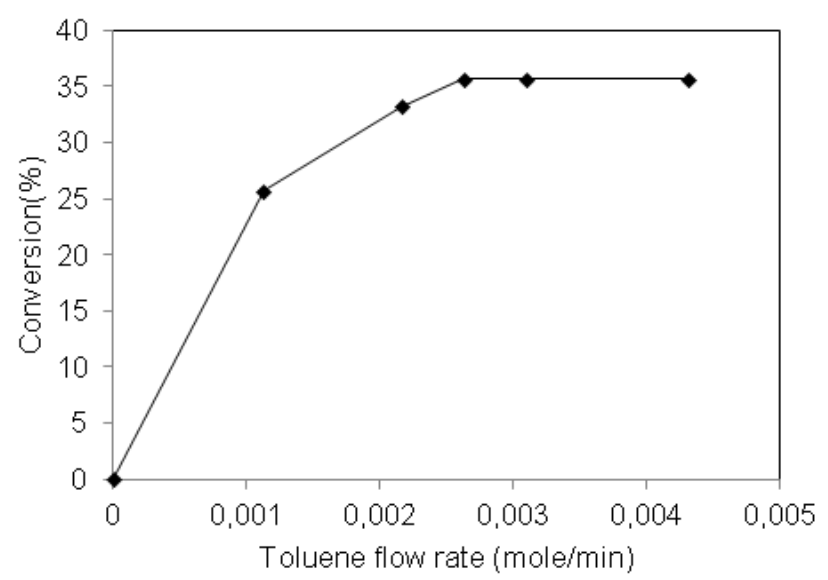

Figure 7. Effect of toluene flow rate on conversion. Reactor temp: $400{ }^{\circ} \mathrm{C}$, weight of catalyst: 1 $\mathrm{g}$, mole ratio of toluene to methanol: 1:2

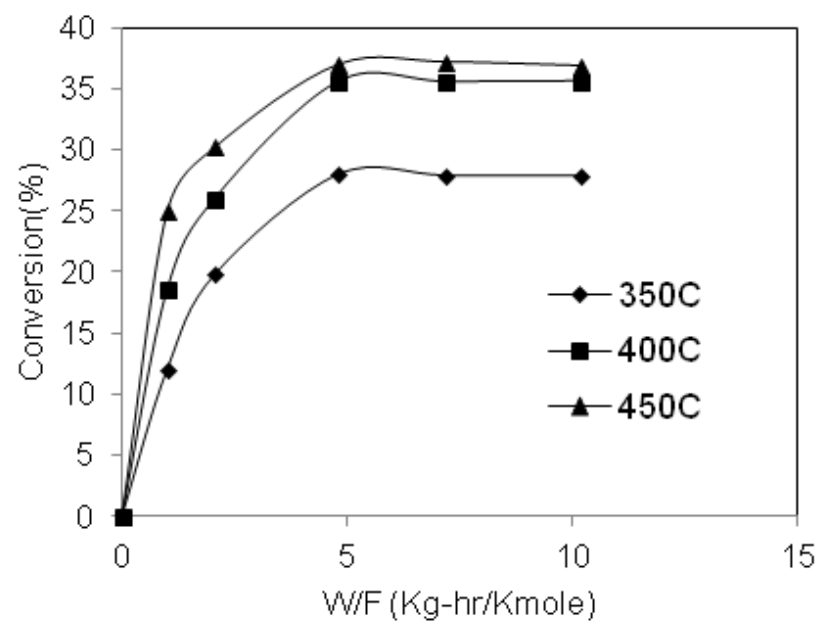

Figure 8. Effect of W/F on conversion

Reactor temp: $400{ }^{\circ} \mathrm{C}$, mole ratio of toluene to methanol: $1: 2, \mathrm{~N}_{2}$ flow rate: $2 \times 10^{-4} \mathrm{~mol} / \mathrm{min}$ 
5 coated 30 ppi $\mathrm{SiC}$ foam. It has been observed that the conversions obtained are 28 and $35.7 \%$ for 10 ppi and 30 ppi foam respectively. This may be because of the greater surface area for 30 ppi than the 10 ppi foam.

\subsection{Time on Stream Conversion with Metal Modified ZSM-5 Coated SiC Foam}

Constancy in toluene conversion up to 55 min of continuous run is observed from Figure 5 for all metal modified ZSM-5 supported on $\mathrm{SiC}$ foam. The almost constant conversions of 35.7, 29.8 and $25.2 \%$ are achieved by La-ZSM5, Ce-ZSM-5 and Nb-ZSM-5 respectively using $1 \mathrm{~g}$ catalyst at $400{ }^{\circ} \mathrm{C}$ with toluene-methanol ratio of 1:2.

These plots confirm that the catalysts are not deactivating up to 45 min of reaction time, which in turn is advantageous for using the catalysts commercially. The catalysts were compared in terms of xylene selectivity which are 98, 95 and 92\% for La-ZSM-5, Ce-ZSM-5 and Nb-ZSM-5 respectively. The reason behind the difference in selectivities of xylene may be due to the decrease in acid sites by metal deposition in pores, which are different for different metals modified catalysts.

Influence of different parameters on the toluene conversion was studied using La-ZSM5 catalysts with $10 \%$ targeted metal loading. The catalyst is represented as La10ZSM-5. The comparison of conversion and selectivity of different catalysts are tabulated in Table 2 .

\subsection{Effect of Different Parameters}

\subsubsection{Effect of temperature on initial con- version of toluene}

Toluene alkylation reaction with methanol was performed varying temperatures in the range of $300-520{ }^{\circ} \mathrm{C}$. The plot of initial conversion with temperature is shown in Figure 6, which shows that conversion increases gradually up to $400{ }^{\circ} \mathrm{C}$, after which it attains a fixed value. Although a slight decrease in conversion is noticed at $520{ }^{\circ} \mathrm{C}$, which may be due to the deactivation of the catalyst at that high temperature. The maximum xylene selectivity (98\%) is observed at $400{ }^{\circ} \mathrm{C}$, but above this temperature selectivity reduces.

\subsubsection{Effect of feed flow rate on toluene conversion}

The variation of feed flow rate at $400{ }^{\circ} \mathrm{C}$ with mole ratio of toluene to methanol 1:2 was carried out by varying flow rate of toluene from 0.001 to $0.0045 \mathrm{~mol} / \mathrm{min}$ which is shown in Figure 7 . The conversion of toluene increases up to the flow rate of $0.0029 \mathrm{~mol} / \mathrm{min}$ and beyond this, the conversion becomes constant. Hence, all subsequent experiments were carried out choosing flow rate $0.0039 \mathrm{~mol} / \mathrm{min}$ to avoid the external mass transfer effect.

\subsubsection{Effect of W/F on toluene conversion}

The kinetic data were generated by varying $\mathrm{W} / \mathrm{F}$ values from 0.6 to $5.5 \mathrm{~kg} . \mathrm{h} / \mathrm{kmol}$ at differ-

Table 3. Results of kinetic model analysis

\begin{tabular}{lcccccc}
\hline Models & $\mathrm{T}(\mathrm{K})$ & $k_{S}$ & $K_{A}$ & $K_{B}$ & $K_{C}$ & Resnorm* \\
\hline Model-1 & 623 & 0.330 & 2.440 & - & 3.70 & 0.0008 \\
& 673 & 1.45 & 0.540 & - & 3.08 & 0.0006 \\
& 703 & 2.45 & 0.320 & - & 2.18 & 0.0011 \\
& 723 & 5.45 & 0.170 & - & 1.21 & 0.0007 \\
\hline Model-2 & 623 & 0.124 & 0.903 & 1.668 & -1.773 & 0.0008 \\
& 673 & -0.79 & 1.938 & 2.585 & -5.234 & 0.0006 \\
& 703 & 0.029 & -1.790 & 3.734 & 2.202 & 0.0013 \\
Model-3 & 723 & 1.300 & 2.360 & 4.300 & 1.500 & 0.0080 \\
& 623 & -3.221 & -1.212 & 3.609 & 0.560 & 0.0005 \\
& 673 & 2.124 & 2.124 & 1.499 & 1.802 & 0.0003 \\
& 703 & 2.211 & 4.14 & 1.488 & 2.292 & 0.0016 \\
& 723 & 1.212 & -1.002 & 1.452 & 3.660 & 0.0013 \\
\hline
\end{tabular}

* Resnorm $=\sum_{i}\left(r_{\text {pred }}-r_{o b s}\right)^{2}$ 
ent temperatures, $350,400,430$ and $450{ }^{\circ} \mathrm{C}$ and shown in Figure 8. For all the temperatures, the nature of the curves shows that the reactor is integral type. These conversion data were used to estimate the rate parameters of various rate models.

\subsection{Kinetic Study}

The alkylation reaction of toluene with methanol to form xylene and water can be represented as:

$$
\begin{aligned}
\mathrm{C}_{6} \mathrm{H}_{5} \mathrm{CH}_{3-}(\mathrm{A})+\mathrm{CH}_{3} \mathrm{OH}(\mathrm{B}) \rightarrow \underset{ }{\mathrm{C}_{6} \mathrm{H}_{5}\left(\mathrm{CH}_{3}\right)_{2}(\mathrm{C})+} & \mathrm{H}_{2}(\mathrm{D})
\end{aligned}
$$

For the formulation of rate model in case of heterogeneous catalysis, Langmuir approach was taken into consideration. Considering water molecules are not adsorbing the following three different controlling steps are assumed:

Model-1: It is considered that 'B' was not adsorbed on catalyst surface and surface reaction is rate controlling (Eley-Riedel mechanism).

$$
-r=\frac{K p_{A} p_{B}}{1+K_{A} p_{A}+K_{C} p_{C}} \text { where, } K=k_{g} K_{A}
$$

Model-2: This model considered dual site mechanism where surface reaction is irreversible and is the rate controlling step.

$$
-r=\frac{K p_{A} p_{B}}{\left(1+K_{A} p_{A}+K_{C} p_{C}\right)^{2}}
$$

where $K=k_{s} K_{A} K_{B}$.

Model-3: This model described the dual site mechanism with adsorption of ' $\mathrm{A}$ ' is the slowest step.

$$
-r=\frac{K p_{A}}{1+\frac{K^{v} p_{C}^{2}}{p_{B}}+K_{B} p_{B}+K_{C} p_{C}}
$$

(3)

where $K^{\prime}=K_{C} K_{D} / k_{s} K_{B}$, and $k_{s}$ is the kinetic constant, $K$ is the equilibrium constant, $K_{A}, K_{B}$, $K_{C}$, and $K_{D}$ are the adsorption equilibrium constants for species A,B C and D, respectively.

\subsection{Analysis of Kinetic Models and Esti- mation of Parameters}

Reaction rate at various conversion levels were calculated from differentiation at various points of W/F versus conversion curves. The parameters were estimated using Matlab 7.9.0 by non-linear method of analysis and the results of the non-linear analysis are shown in Table 3.
The parameters in case of Model 2 and 3 are found to be negative and hence those two models are rejected, whereas, Model 1, the surface reaction controlling rate equation was satisfactorily fitted to the experimental data. Hence, Model 1 is chosen as the rate equation is chosen as the rate equation.

The values of rate constant, $\mathrm{k}_{\mathrm{S}}$ obtained from Model 1, were fitted to Arrhenius equation. The apparent activation energy and frequency factor are found to be $47 \mathrm{~kJ} / \mathrm{mol}$ and 5.4 $\times 10^{4} \mathrm{kmol} / \mathrm{kg} . \mathrm{h}$.

\subsection{Reusability of Catalyst}

The used catalyst blocks were regenerated by heating in a furnace at $600{ }^{\circ} \mathrm{C}$ for $6 \mathrm{~h}$. After regeneration, the catalyst was reused in the reaction at same reaction condition as the fresh one. The regeneration and reaction were repeated three times and no appreciable difference in conversion is observed even after repeated use of the catalyst. The conversion after $1^{\text {st }}, 2^{\text {nd }}$ and $3^{\text {rd }}$ regeneration were observed to be $35.3,34.9$ and $34.5 \%$ respectively where, the conversion using fresh catalyst was $35.7 \%$. Therefore, it could be said that, the catalyst can be reused successfully for several times.

\section{Conclusions}

The behavior of toluene methylation reaction using ZSM- 5 catalyst by modification with lanthanum, cerium and niobium oxides has been studied. The physical properties of the modified catalysts were analysed and a decrease in surface area and pore volume were found to decrease compared to the unmodified ZSM-5 catalyst. The catalysts were coated on silicon carbide foam of 30 ppi and the conversion of toluene using the coated and pelleted catalysts were compared. The foam coated catalysts showed better conversion and lanthanum modified ZSM-5 coated foam catalyst showed best selectivity towards the desired product $\mathrm{xy}$ lene. The kinetic experiments were conducted with foam-coated lanthanum catalyst and Langmuir Hinshelwood model with dual site surface reaction controlling step is found to fit well with the experimental data. The activation energy was found to be $47 \mathrm{~kJ} / \mathrm{mol}$. 


\section{References}

[1] Aboul-Gheit, A.K., Abdel-Hamid, S.M., Emam, E.A. (1999). Catalytic para-xylene maximization II - alkylation of toluene with methanol on platinum loaded H-ZSM-5 zeolite catalysts prepared via different routes. Appl. Catal. A: Gen. 179: 107-115.

[2] Aboul-Gheit, A.K., Awadallah, A.E., AboulEnein, A.A., Mahmoud, A.L.H. (2011). Molybdenum substitution by copper or zinc in $\mathrm{H}$ ZSM-5 zeolite for catalyzing the direct conversion of natural gas to petrochemicals under non-oxidative conditions. Fuel. 90: 3040-3046.

[3] Madhavi, G., Kulkarni, S.J., Murthy, KVVSBSR, Viswanathan, V., Raghavan, K.V. (2003). Side-chain alkylation of 4-picoline with formaldehyde over alkali-modified zeolites. Appl. Catal. A: Gen. 246: 265-282.

[4] Choudhary, V.R., Jana, S.K., Mamman, A.S. (2002). Benzylation of benzene by benzyl chloride over Fe-modified ZSM-5 and $\mathrm{H}$-b zeolites and $\mathrm{Fe}_{2} \mathrm{O}_{3}$ or $\mathrm{FeCl}_{3}$ deposited on micro-, mesoand macro-porous supports. Microporous and Mesoporous Materials. 56 : 65-71.

[5] Díaz, E., Ordo'ñez, S., Vega, A., Auroux, C.J. (2005). Benzylation of benzene over Femodified ZSM-5 zeolites: Correlation between activity and adsorption properties. Appl. Catal. A: Gen. 295 :106-115.

[6] Barros, I.C.L., Braga, V.S., Pinto, D.S., de Macedo, J.L., Filho, G.N.R., Dias, J.A., Dias, S.C.L. (2008). Effects of niobium addition on ZSM-5 studied by thermal and spectroscopy methods. Microporous and Mesoporous Materials. 109: 485-493.

[7] Prasetyoko, D., Ramli, Z., Endud, S., Nur, H. (2008). Characterization and Catalytic Performance of Niobic Acid Dispersed over Titanium Silicalite. Adv. Mat. Sci. Eng. 345895: 112.

[8] Moreira, C.R., Pereira, M.M., Alcobe, X., Homs, N., Llorca, J., Fierro, J.L.G., Ramirez de la Piscina, P. (2007). Nature and location of cerium in Ce-loaded $\mathrm{Y}$ zeolites as revealed by HRTEM and spectroscopic techniques. $M i$ croporous and Mesoporous Materials. 100: 276-286.

[9] Kim, J.H., Sugi, Y., Matsuzaki, T., Hanaoka, T., Kubota, Y., Tu, X., Matsumoto, M., Nakata, S., Kato, A., Seo, G., Pak, C. (1995). Cerium impregnated $\mathrm{H}$-mordenite as a catalyst for shape-selective isopropylation of naphthalene. Selective deactivation of acid sites on the external surface. Appl. Catal. A: Gen. 131: 15-32.
[10] Liu, S., Wang, L., Ohnishi, R., Ichikawa, M. Bifunctional Catalysis of Mo/HZSM-5 in the (1999). Dehydroaromatization of Methane to Benzene and Naphthalene XAFS / TG / DTA / MASS / FTIR Characterization and Supporting Effects. J. Catal. 181:175-188.

[11] Kalita, P., Gupta, N.M., Kumar, R. (2007). Synergistic role of acid sites in the Ceenhanced activity of mesoporous Ce-Al-MCM41 catalysts in alkylation reactions: FTIR and TPD-ammonia studies. J. Catal. 245: 338-347.

[12] Hartford, R.W., Kojima, M., O'Connor, C.T. (1989). Lanthanum Ion Exchange on H-ZSM5. Ind. Eng. Chem. Res., 28 (12): 1748-1752.

[13] Richardson, J.T., Garrait, M., Hung, J.K. (2003). Carbon dioxide reforming with $\mathrm{Rh}$ and $\mathrm{Pt}-\mathrm{Re}$ catalysts dispersed on ceramic foam supports. Appl. Catal. A: Gen. 255 : 69-82.

[14] Wahlen, J., Hertogh, S.D., De Vos DE, Nardello, V., Bogaert, S., Aubry, J.M., Alsters, P.L., Jacobs, P.A. (2005). Disproportionation of hydrogen peroxide into singlet oxygen catalyzed by lanthanum-exchanged zeolites. J. Catal. 233: 422-433.

[15] Yang, F.K., Wang, S.M., Xia, Y.M., Bi, W.H., Wang, W. (2011). Study on Methanol Aromatization over Zeolite Catalyst H/ZSM-5 Modified with Zinc Ions in Different Contents. Petroleum Sci. Technol. 29(16): 1675-1684.

[16] Youming, N.I., Aiming, S.U.N., Xiaoling, W.U., Jianglin, H.U., Tao, L.I., Guangxing, L.I. (2011). Aromatization of Methanol over La/Zn/HZSM-5 Catalysts. Chinese J. Chem. Eng., 19(3): 439-445.

[17] Bendahou, K., Cherif, L., Siffert, S., Tidahy, H.L., Benaissa, H., Aboukais, A. (2008). The effect of the use of lanthanum-doped mesoporous SBA-15 on the performance of Pt/SBA-15 and $\mathrm{Pd} / \mathrm{SBA}-15$ catalysts for total oxidation of toluene. Appl. Catal. A: Gen. 351: 82-87.

[18] Inoue, K., Okabe, K., Liu, Y., Inaba, M., Takahara, I., Murata, K. (2011). Synergistic Effects of Lanthanum and Magnesium Additive to H-ZSM-5 for Ethanol Conversion to Propylene. J. Japan Petrol Inst., 54 (6): 390-394.

[19] Bhure, M.H., Kumar, I., Natu, A.D., Chikate, R.C., Rode, C.V. (2008). Phosphotungstic acid on silica with modified acid sites as a solid catalyst for selective cleavage of tert-butyldimethylsilyl ethers. Catal Comm. 9: 18631868 . 